\title{
Tensile Strength of Geological Discontinuities Including Incipient Bedding, Rock Joints and Mineral Veins
}

\author{
J. Shang ${ }^{1}$ S. R. Hencher ${ }^{1,2,3} \cdot$ L. J. West ${ }^{1}$
}

Received: 11 December 2015/ Accepted: 23 June 2016/Published online: 2 July 2016

(c) The Author(s) 2016. This article is published with open access at Springerlink.com

\begin{abstract}
Geological discontinuities have a controlling influence for many rock-engineering projects in terms of strength, deformability and permeability, but their characterisation is often very difficult. Whilst discontinuities are often modelled as lacking any strength, in many rock masses visible rock discontinuities are only incipient and have tensile strength that may approach and can even exceed that of the parent rock. This fact is of high importance for realistic rock mass characterisation but is generally ignored. It is argued that current ISRM and other standards for rock mass characterisation, as well as rock mass classification schemes such as RMR and Q, do not allow adequately for the incipient nature of many rock fractures or their geological variability and need to be revised, at least conceptually. This paper addresses the issue of the tensile strength of incipient discontinuities in rock and presents results from a laboratory test programme to quantify this parameter. Rock samples containing visible, natural incipient discontinuities including joints, bedding, and mineral veins have been tested in direct tension. It has been confirmed that such discontinuities can have high tensile strength, approaching that of the parent rock. Others are, of course, far weaker. The tested geological discontinuities all exhibited brittle failure at axial strain less than $0.5 \%$ under direct tension conditions. Three factors contributing to the tensile
\end{abstract}

S. R. Hencher

stevehencher@btinternet.com

1 Geomechanics Research Group, School of Earth and Environment, University of Leeds, Leeds, UK

2 Department of Earth Sciences, University of Hong Kong, Pok Fu Lam, Hong Kong, SAR, China

3 Hencher Associates Limited, Ilkley, UK strength of incipient rock discontinuities have been investigated and characterised. A distinction is made between sections of discontinuity that are only partially developed, sections of discontinuity that have been locally weathered leaving localised residual rock bridges and sections that have been 'healed' through secondary cementation. Tests on bedding surfaces within sandstone showed that tensile strength of adjacent incipient bedding can vary considerably. In this particular series of tests, values of tensile strength for bedding planes ranged from 32 to $88 \%$ of the parent rock strength (intact without visible discontinuities), and this variability could be attributed to geological factors. Tests on incipient mineral veins also showed considerable scatter, the strength depending upon the geological nature of vein development as well as the presence of rock bridges. As might be anticipated, tensile strength of incipient rock joints decreases with degree of weathering as expressed in colour changes adjacent to rock bridges. Tensile strengths of rock bridges (lacking marked discolouration) were found to be similar to that of the parent rock. It is concluded that the degree of incipiency of rock discontinuities needs to be differentiated in the process of rock mass classification and engineering design and that this can best be done with reference to the tensile strength relative to that of the parent rock. It is argued that the science of rock mass characterisation may be advanced through better appreciation of geological history at a site thereby improving the process of prediction and extrapolating properties.

Keywords Geological discontinuities - Incipiency · Persistence - Rock bridges - Uniaxial tensile strength · Laboratory testing $\cdot$ Rock mass classification $\cdot$ Fracture development 


\section{Introduction}

The International Society for Rock Mechanics (ISRM 1978a) defines 'discontinuity' as the generic term for mechanical fractures in a rock mass that has zero or low tensile strength. It is applied to such geological features as open joints, weak bedding planes, weak schistosity planes, weakness zones and faults. In practice, the term is also often applied to any visible geological planar features (including joints and veins) that can be observed in exposures, in tunnels, in borehole walls, on photographs or measured by ground radar scans even where these features might and often do retain high strength and therefore strictly fall outside the ISRM definition of a discontinuity. In a similar way, whilst only open natural discontinuities should be counted when determining Rock Quality Designation (RQD) as defined by Deere (1968) and Deere and Deere (1989), in practice incipient discontinuities are also included in the assessment, especially where dealing with rock exposures rather than logging core. This might be a conservative approach in some situations (rock mass would be stronger and stiffer than that assumed on the basis of the assigned RQD value) but certainly would give an inaccurate representation of rock mass quality. This will of course have 'knock-on' consequences when using RQD as part of assessment of rock mass quality, likely behaviour, say, in tunnel stability, and in determining numerical parameters on the basis of empiricism. Where the presence of open fractures is relied upon, say for open excavation or tunnelling using a roadheader, misrepresenting incipient discontinuities as if they lacked tensile strength in site investigation descriptions, can lead to misunderstandings, poor selection of equipment and contractual disputes (Hencher 2014, 2015). A separate but important conceptual point is that incipient discontinuities will propagate and weaken over geological and engineering time as the result of processes such as unloading and weathering (Hencher 2006; Hencher and Knipe 2007); the tests reported in this paper need to be considered in this context of a developmental process for discontinuities. Any discontinuity observed in the field is at a particular stage of development and if we are to characterise such discontinuities we need to appreciate that their properties reflect long and often complex, site-specific histories.

This is not a trivial observation as incipient rock discontinuities often have a controlling influence on rock mass strength and stability. Tensile or shear failure of incipient sections of fractures is often the 'final straw' leading to instability. In exposures and tunnel roofs, many overhanging and threatening rock blocks or slabs remain in place solely due to the incomplete development of the bounding discontinuities as illustrated in Fig. 1.

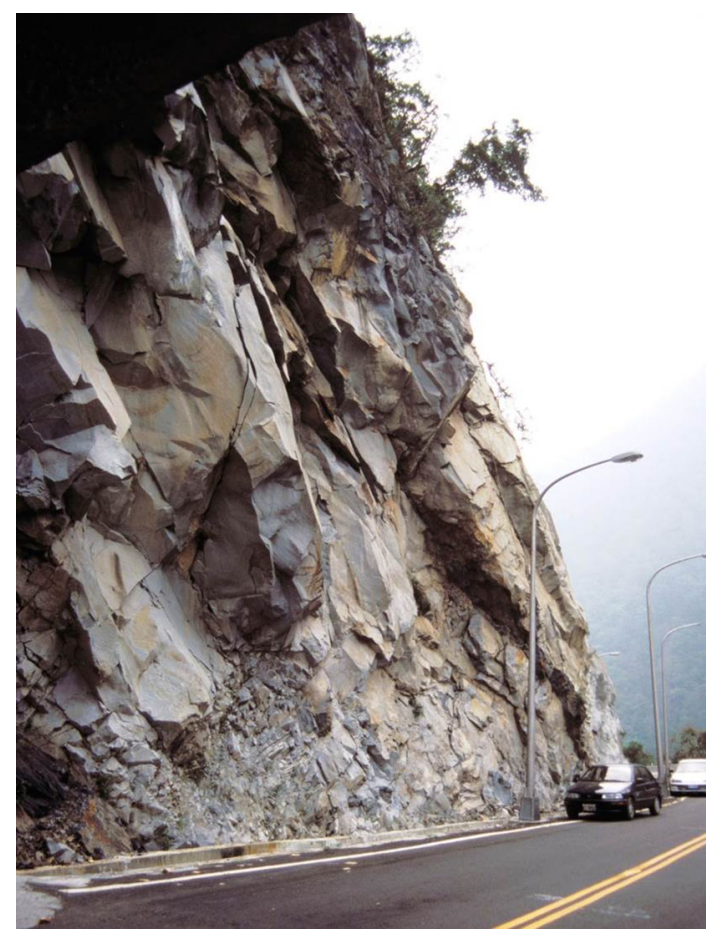

Fig. 1 Slope with daylighting rock slabs threatening highway in central Taiwan. The incipient nature of the discontinuities contributes tensile and shear strength and allows temporary stability

The concept of incipient joints is illustrated in Fig. 2 which shows joints at various stages of development in granite, as exposed on a quarry face cut by a diamond wire saw. Joints 1 and 2 can be clearly seen as discrete discoloured traces but are only faintly defined as weaknesses. Joint 3 is more fully developed and has one section that is open, allowing seepage of water. Despite its obvious importance, degree of incipiency (which is common to all rock types) is extremely difficult to assess or extrapolate which is probably why it has been largely ignored in the literature or put into the 'too difficult' box. There have been some attempts at quantification. For example, Cravero and Iabichino (2004) discussed the flexural failure of a gneissic slab from a quarry face after at least 15 years of exposure. They concluded that the slab failed in tension initiated by either water pressure or seismic loading. Paronuzzi and Serafini (2009) assessed the stress state of a collapsed overhanging rock slab previously connected to the rest of the rock mass by an incipient joint (see Fig. 3). The area of rock bridge revealed after collapse was $2.82 \mathrm{~m}^{2}$, and a value for the tensile strength of the bridge was back-calculated using 3D numerical analysis as $\sigma_{\mathrm{t}}=5.19 \mathrm{MPa}$.

In the view of the authors, relating the nature and development of incipient discontinuities to their geological histories is an exciting research area with major potential 


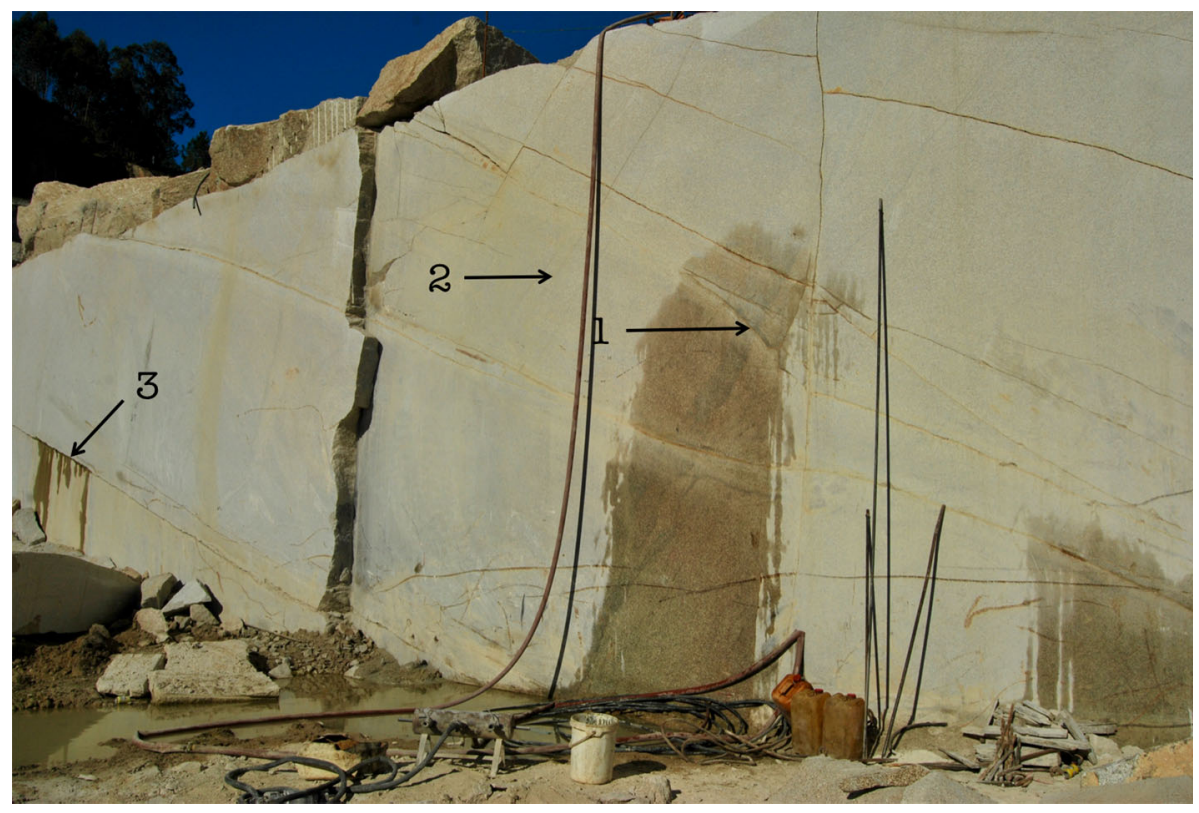

Fig. 2 Face cut by diamond wire saw in dimension stone quarry near Tui, Galicia, Spain. Sets of joints can be seen as linear traces stained with iron oxides, cutting the granite. These joints were evidently formed from brittle fracture propagation at a late stage during cooling/ emplacement of the granite as can be interpreted from cross-cutting relationships and the geometrical association of some joints with mineral differentiation (as at 1 in an area washed off with water). Note that some of the joints are poorly defined and terminate (as visible features) as at 2 . The joint pattern is a 'blueprint' that, given time, would propagate as interconnecting true, mechanical discontinuities in the sense defined by ISRM. Note at 3 that one of the shallowly dipping joints (not-sheeting), has an open aperture locally, allowing seepage of groundwater. Thanks are due to Professor Leandro Alejano and his student Ignacio Pérez Rey for introducing the quarry and for constructive discussions in the field with the second author
Fig. 3 General view of a collapsed overhanging limestone slab located at northern part of Cellina Valley gorge on 26 January 1999. A rock bridge (red-hatched area) was exposed after failure (colour figure online)

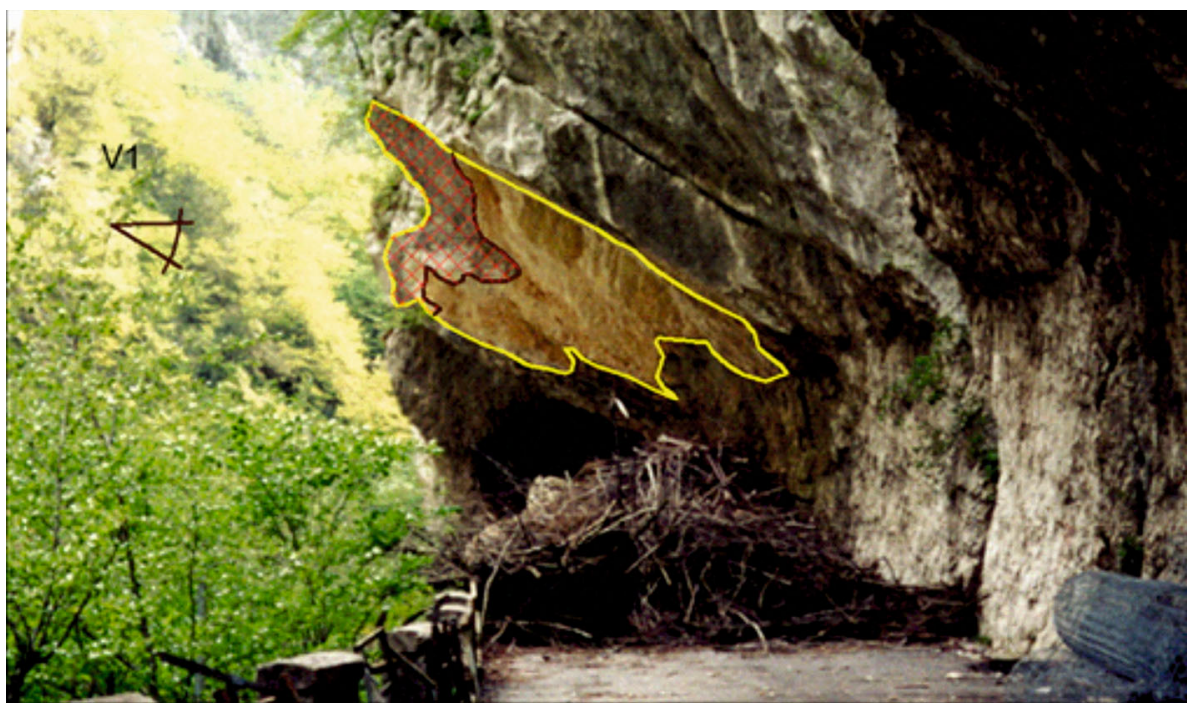

for impacting many rock-engineering problems. These include such diverse areas as rock slope engineering, the characterisation of large volumes of rock mass for nuclear waste disposal and for oil and gas reservoir engineering. This paper describes preliminary attempts to measure directly and to interpret the tensile strength of different types of incipient discontinuities.

\section{Tensile Testing of Rock}

Laboratory investigations have been carried out into the tensile strength of incipient geological discontinuities including bedding, mineral veins and joints using a uniaxial pulling arrangement (ISRM 1978b). Numerous authors have conducted uniaxial tension tests on intact rocks 
(Hawkes et al. 1973; Okubo and Fukui 1996; Li et al. 2013; Liu et al. 2014; Erarslan and Williams 2012). Saiang et al. (2005) carried out uniaxial tension tests on the bond between shotcrete and rock. A number of authors have tested samples incorporating incipient discontinuities in a general way. Barla and Innaurato (1973) and Dan et al. (2013) found that tensile strength decreased with the increase of the discontinuity orientation relative to the uniaxial loading direction (from $0^{\circ}$ to $90^{\circ}$ ). Khan and Irani (1987) investigated the dynamic tensile strength of samples that were cored perpendicular to bedding planes. In their tests, the split Hopkinson bar was used to apply dynamic loads.

\section{Test Set-Up}

\subsection{Specimen Preparation}

Large rock blocks containing incipient discontinuities were collected from two locations. Samples of siltstone with incipient mineral veins were taken from Dry Rigg Quarry, Horton-in-Ribblesdale, North Yorkshire, UK. The Silurian, Horton rocks are typically medium-to-dark grey sandy siltstone with carbonaceous debris (King 1934; Arthurton et al. 1988; Aitkenhead et al. 2002). Samples of mediumgrained sandstone containing incipient bedding planes and joints were collected from Blackhill Quarry, West Yorkshire, UK. The sandstone is from the Carboniferous Midgley Grit formation and ranges from fine- to very coarsegrained sandstone (Stevenson and Gaunt 1971; Waters et al. 1996).
Two sets of tests were conducted. The first comprised siltstone specimens (50 and $70 \mathrm{~mm}$ in diameter) containing mineral veins. The second set comprised both laminated sandstone samples (70 $\mathrm{mm}$ in diameter) containing incipient bedding planes and apparently uniform samples, some of which contained incipient joints (Fig. $4 c_{1}-c_{3}$ ). Sample were cored perpendicular to incipient discontinuities as illustrated in Fig. 4. Sample ends were ground flat. In this type of test, alignment and gripping of samples are the main problems but, in addition, minor sample inhomogeneity can result in bending and stress concentration (Pells 1993). For this study 'araldite' epoxy resin with tensile strength of more than $20 \mathrm{MPa}$ was employed to cement metal caps to the sample ends and steel chains used as linkage systems to minimise the effect of bending and torsion following the methodologies of Liao et al. (1997), Kwansniewski (2009), Wang (2009) and Mier and Shi (2002).

\subsection{Testing Apparatus Set-Up and Verification}

A servo-controlled loading machine (MAND), with a capacity of $250 \mathrm{kN}$, was used for the uniaxial tensile testing as illustrated schematically in Fig. 5b. Figure 5a shows the experimental set-up for a sample with an incipient mineral vein. In each test, the sample was loaded uniformly at the loading rate of $40 \mathrm{~N} / \mathrm{s}$ until failure. Strain was calculated by dividing the displacement of the loading platens by sample length, while elongation of the chains was deducted for the calculation.

To validate the test set-up, some preliminary tests were carried out on ostensibly homogeneous samples of
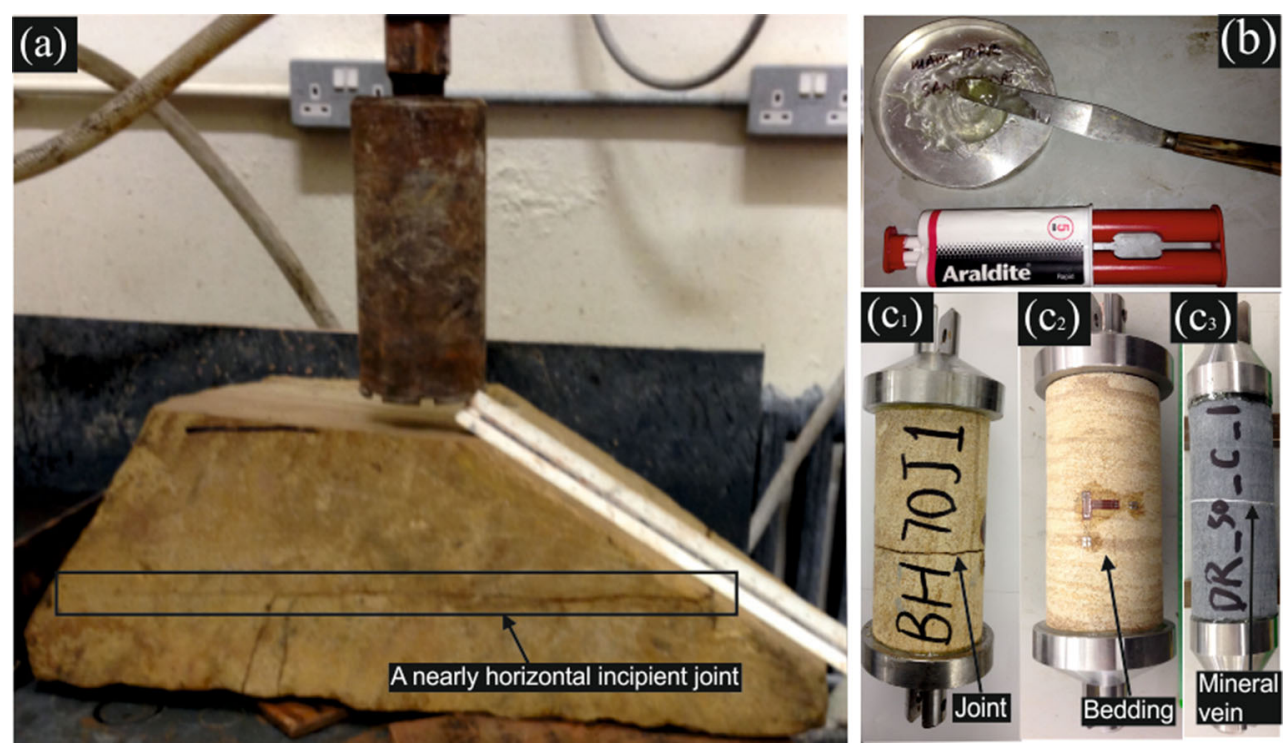

Fig. 4 Sample preparation. a Sandstone cores drilled perpendicular to an incipient joint within a large size sandstone block. b Araldite was used to cement metal caps to sample ends. Samples containing a single visible joint $\left(c_{1}\right)$, bedding planes $\left(c_{2}\right)$ and a mineral vein $\left(c_{3}\right)$ 
Fig. 5 a Photograph of the experimental setup on a sample containing a single incipient mineral vein and $\mathbf{b}$ schematic diagram of set-up for uniaxial tension test (not to scale)
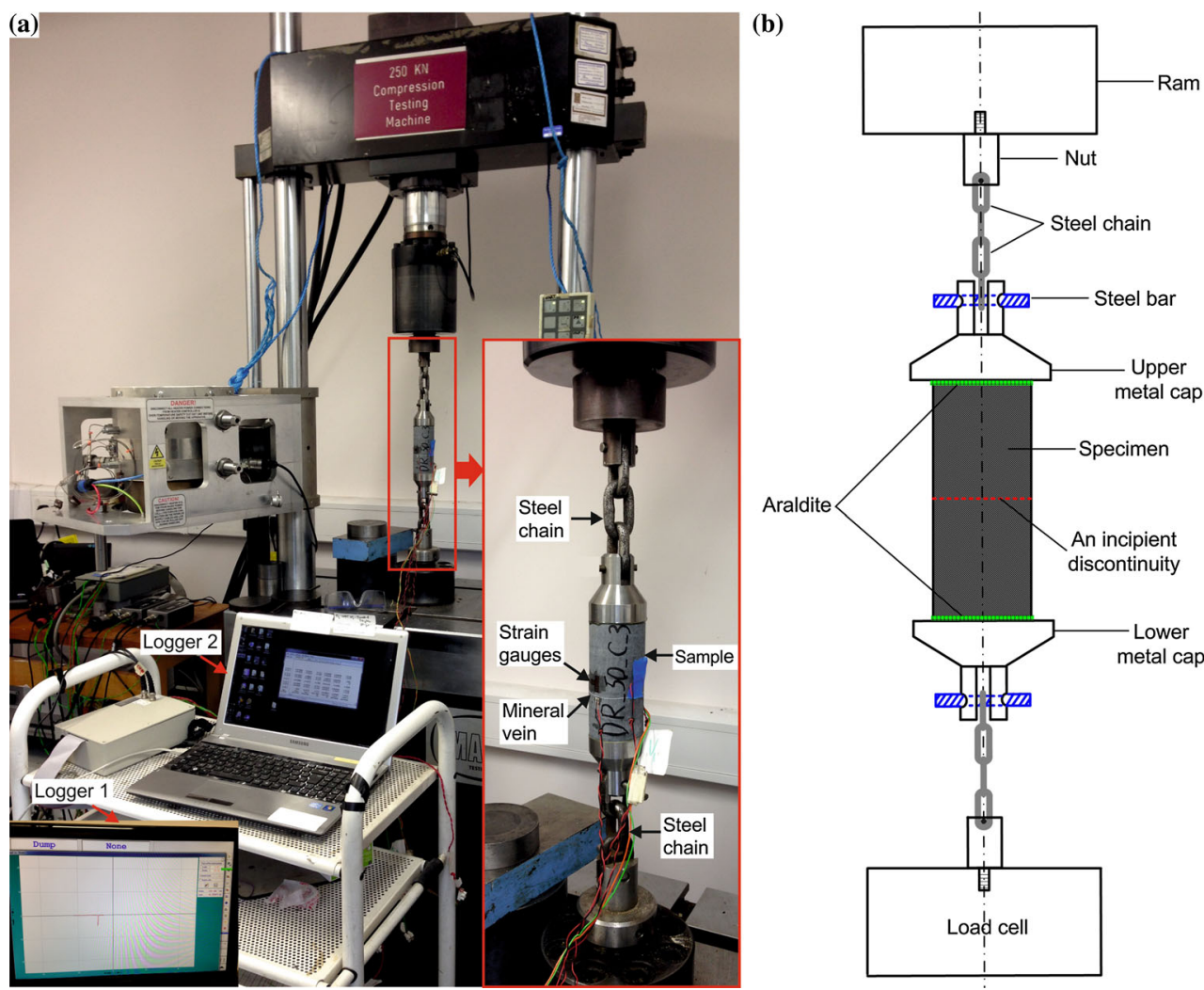

Blackhill Quarry sandstone (lacking visible fabric), using a similar set-up to that of Okubo and Fukui (1996) and Hashiba and Fukui (2014). Four strain gauges $(10 \mathrm{~mm}$ in length) were attached to the middle of the specimens. Figure 6 shows the nature of failure for one sample. Microstrain curves plotted against time (Fig. 7) for this test confirm similar strain at the four measurement locations, which provides some confidence in the alignment of the testing set-up as used for the subsequent uniaxial tension tests on incipient discontinuities. Brazilian tests were also conducted on a series of similar homogeneous samples of the sandstone as illustrated in Fig. 8. Data presented in Table 1 show that the average measured tensile strength for samples tested uniaxially was $2.08 \mathrm{MPa}$; the Brazilian test results were generally slightly higher with an average of $2.44 \mathrm{MPa}$. This finding agrees well with the conclusion in the work by Perras and Diederichs (2014) in which Brazilian tensile strength of sedimentary rock consistently showed a higher value (10-30\% higher) than the uniaxial tensile strength. The differences perhaps reflect aspects of the process of fracture initiation and propagation in the different testing methods and the way that strength is calculated, but further work would be necessary to establish whether there is some consistent explanation. For the purposes of this current work, it is sufficient to observe that the uniaxial test setup gave results that are broadly consistent with the Brazilian test.
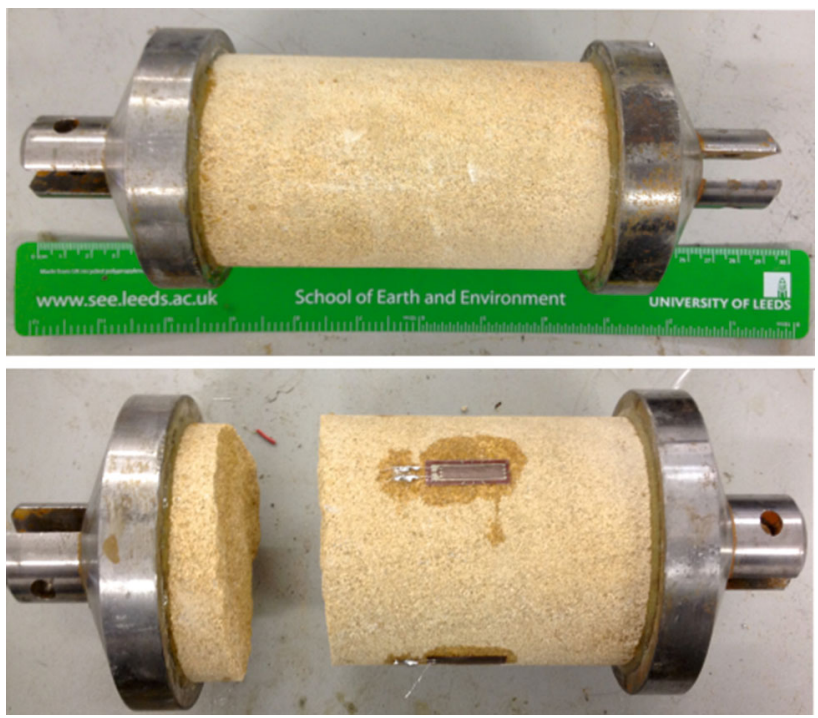

Fig. 6 Ostensibly homogeneous sandstone sample before and after uniaxial tensile test

\section{Direct Tension Tests on Incipient Discontinuities}

\subsection{Samples with Incipient Bedding Planes}

A series of uniaxial tension tests were conducted on laminated sandstone samples with incipient bedding planes 


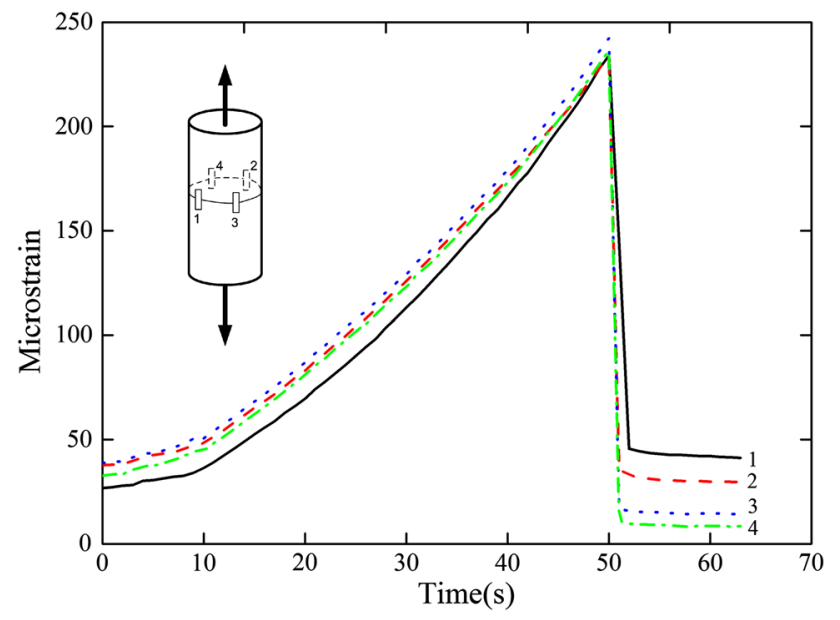

Fig. 7 Micro-strain vs time curves for verification tests for uniaxial tension set-up. Four strain gauges were affixed as shown on the diagram

approximately perpendicular to the loading axis. In some cases, after testing, samples were glued together again by araldite (generally stronger than the rock laminations) and the sample retested. In others, where the failure occurred close to a platen, the sample was cut flat and ground prior to gluing the platen on the fresh surface. Following this experimental technique, in each subsequent test run, the samples failed along progressively stronger discontinuities. Table 2 lists tensile strengths for failures on incipient bedding planes and these strengths are expressed as a proportion of the strength of the homogeneous parent rock tested in the same manner (Table 1). The UTS of the weakest bedding plane tested in this way was $0.67 \mathrm{MPa}$, which is approximately $32 \%$ that of the parent rock. The strength of the strongest incipient bedding plane on which failure occurred was $1.82 \mathrm{MPa}$, which is about $88 \%$ the tensile strength of the intact sandstone. Average UTS of incipient bedding planes from these tests on Blackhill sandstone was $1.45 \mathrm{MPa}$ with a standard deviation of $0.4 \mathrm{MPa}$, i.e. about $70 \%$ of the intact rock UTS. The listed data show that measured tensile strengths increased progressively with reducing sample height as samples were trimmed and reset. For example, specimen BH1-1 with an original height of $149 \mathrm{~mm}$ failed at $0.67 \mathrm{MPa}$. For the second test on this same sample (but now lacking the weakest incipient discontinuity) the UTS was $1.22 \mathrm{MPa}$ and then progressively 1.69 and $1.82 \mathrm{MPa}$. The weakest link failed first, followed by progressively stronger surfaces though the same sample.

Stress-strain relationships of sample BH1 are shown in Fig. 9 together with photographs of the failure at each stage. The stress-axial strain curves represent the full sample length, rather than locally at the strain gauges. These curves are essentially linear up to failure.

\subsection{Samples with Incipient Joints}

Direct tension tests were conducted on samples of ostensibly homogeneous of Blackhill sandstone containing incipient joints, with the samples drilled so that the joints were approximately orthogonal to the tensile force. Stress versus axial strain curves are presented in Fig. 10. The inset photographs illustrate that failure always occurred along the incipient joint planes. All six samples with incipient joints underwent brittle failure at a relatively low axial strain (0.05-0.2\%) compared to some of the tests on incipient bedding planes (Fig. 9). Table 3 shows that UTS values for these incipient joints varied from $0.48 \mathrm{MPa}$ (sample BH70J2) to $1.34 \mathrm{MPa}$ (sample BH70J5).

The joint surfaces were described using a four-colour classification: light-brown (LB), reddish-brown (RB),
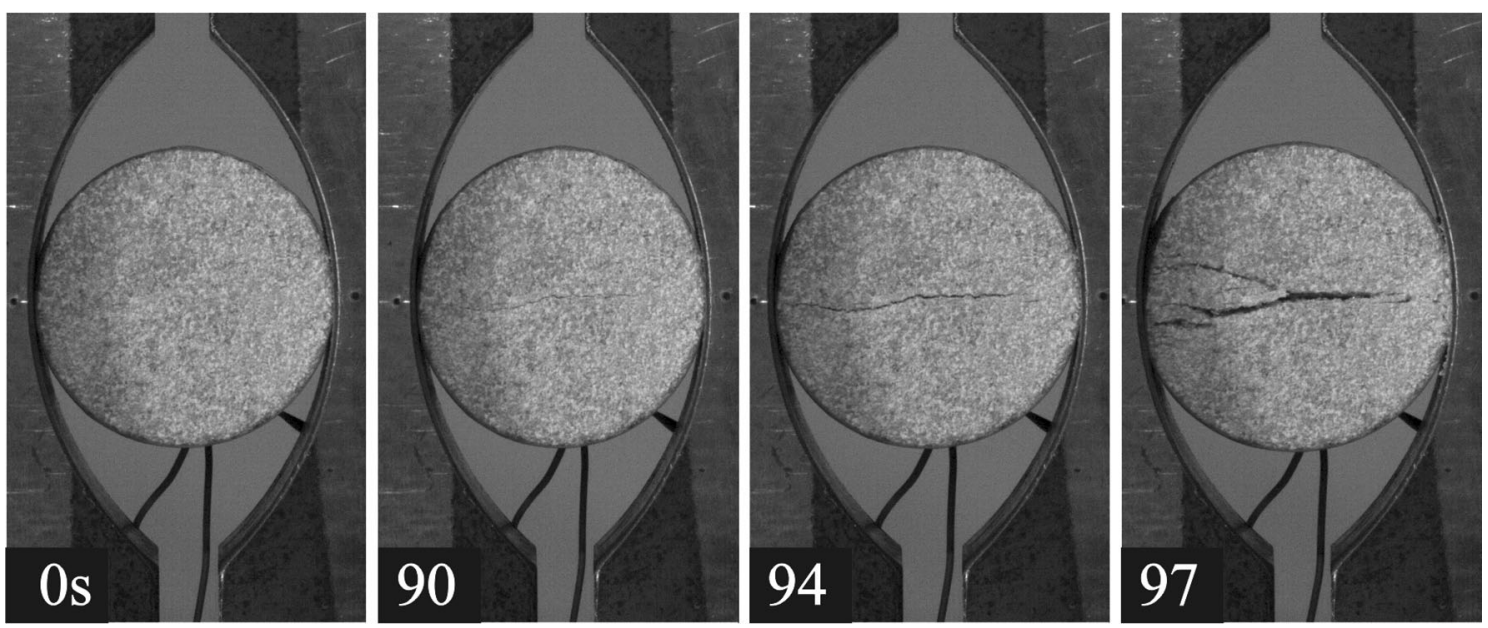

Fig. 8 Fracture initiation and propagation within an intact sandstone sample during a Brazilian tension test. Loading was applied horizontally relative to the photographs, which were taken using a high-speed camera (numbers are seconds from test initiation) 
Table 1 Tensile strength of homogeneous sandstone samples from uniaxial direct tension and Brazilian splitting tests

\begin{tabular}{lll}
\hline Sample & $\begin{array}{l}\text { Tensile strength } \\
(\mathrm{MPa})\end{array}$ & $\begin{array}{l}\text { Average tensile } \\
\text { strength (MPa) }\end{array}$ \\
\hline Uniaxial tension test & & \\
U-1 & 2.05 & 2.08 \\
U-2 & 1.98 & \\
U-3 & 1.83 & \\
U-4 & 2.08 & \\
U-5 & 2.36 & \\
U-6 & 2.15 & \\
Brazilian test & & \\
B-1 & 2.52 & \\
B-2 & 2.29 & \\
B-3 & 2.37 & \\
B-4 & 2.54 & \\
B-5 & 2.49 & \\
\hline
\end{tabular}

Table 2 Tensile strength of incipient bedding planes

\begin{tabular}{lllll}
\hline Sample & $\begin{array}{l}\text { Height } \\
(\mathrm{mm})\end{array}$ & $\begin{array}{l}\text { Tensile } \\
\text { strength } \\
(\mathrm{MPa})\end{array}$ & $\begin{array}{l}\text { Percentage to } \\
\text { UTS of intact } \\
\text { rock }(\%)\end{array}$ & $\begin{array}{l}\text { Average } \\
\text { tensile strength } \\
(\mathrm{MPa})\end{array}$ \\
\hline BH1-1 & 149 & 0.67 & 32.2 & 1.45 \\
BH1-2 & 132 & 1.22 & 58.7 & \\
BH1-3 & 112 & 1.69 & 81.3 & \\
BH1-4 & 110 & 1.82 & 87.5 & \\
BH2-1 & 152 & 1.51 & 72.6 & \\
BH2-2 & 150 & 1.79 & 86.1 & \\
\hline
\end{tabular}

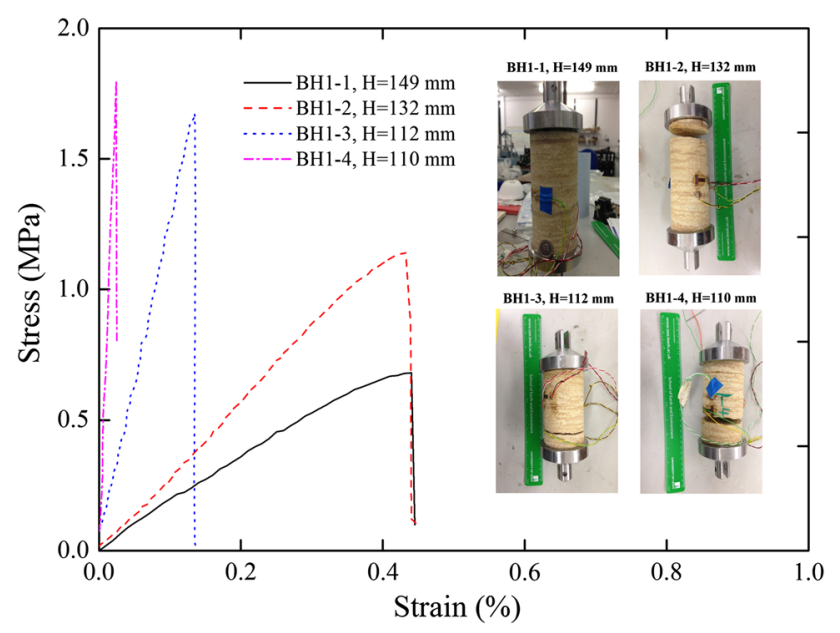

Fig. 9 Stress versus axial strain curves of a single sample containing incipient bedding planes, tested under uniaxial tension

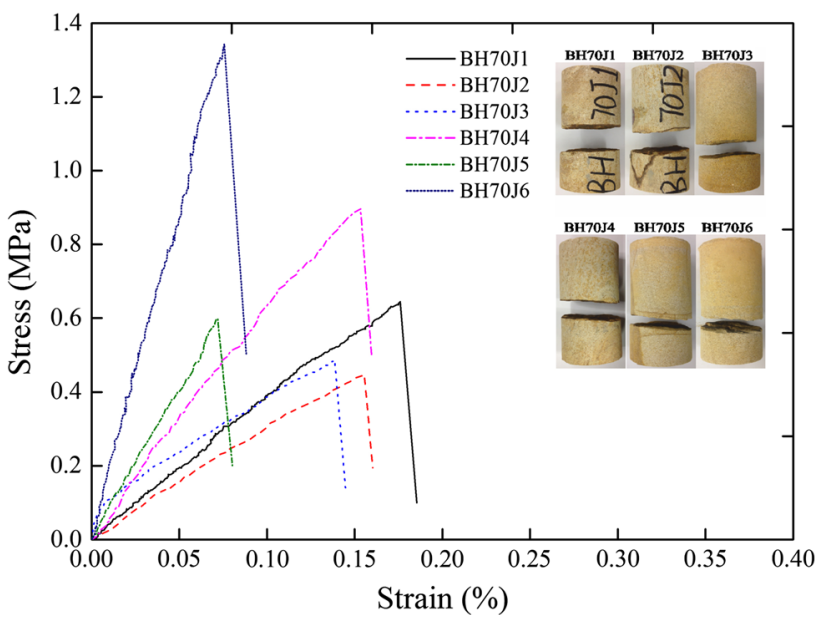

Fig. 10 Stress versus axial strain curves for different samples, each containing a single, visible incipient joint, under uniaxial tension

Table 3 Tensile strength of incipient rock joints

\begin{tabular}{lllll}
\hline Sample & $\begin{array}{l}\text { Diameter } \\
(\mathrm{mm})\end{array}$ & $\begin{array}{l}\text { Tensile } \\
\text { strength } \\
(\mathrm{MPa})\end{array}$ & $\begin{array}{l}\text { Percentage to } \\
\text { UTS of intact } \\
\text { rock }(\%)\end{array}$ & $\begin{array}{l}\text { UTS of rock } \\
\text { bridges } \\
(\mathrm{MPa})\end{array}$ \\
\hline BH70J1 & 70 & 0.63 & 30.3 & 2.10 \\
BH70J2 & 70 & 0.48 & 23.1 & 2.09 \\
BH70J3 & 70 & 0.90 & 42.3 & 2.14 \\
BH70J4 & 70 & 0.55 & 26.4 & 2.12 \\
BH70J5 & 70 & 1.34 & 64.4 & 2.09 \\
BH70J6 & 70 & 0.60 & 28.8 & 2.07 \\
\hline
\end{tabular}

Rock bridge areas are approximate as shown in Fig. 11

greyish-brown (GR) and black-mottled (B) as illustrated in Fig. 11. The light-brown areas were interpreted as areas of rock bridges and these ranged from approximately $23 \%$ to $70 \%$ of the total area for different samples. The other colours indicated the presence of iron oxide (weakly cementing) in otherwise persistent, open sections of discontinuity. The iron oxide coatings are associated with the general chemical weathering process (including propagation and opening up of incipient joints). In the final column of Table 3, the UTS of the interpreted rock bridge areas are listed, calculated on the assumption that all of the measured tensile strength in each test was derived from the rock bridges. The reasoning is supported in that the calculated values (2.07-2.14 MPa) are similar to that measured for samples of intact homogeneous sandstone (Table 1). This result confirms that the variability in tensile strength between joints of different degrees of incipiency relates directly to the area of rock bridge. In these tests the mineral coatings over non-bridge areas contributed very little to the measured tensile strength although it is acknowledged that precipitation of iron oxides in some joints 
Fig. 11 Photograph of incipient joint surfaces after failure in uniaxial tension (top images); classification of surfaces according to colour (lower images) which may reflect the degrees of weathering. More details see text

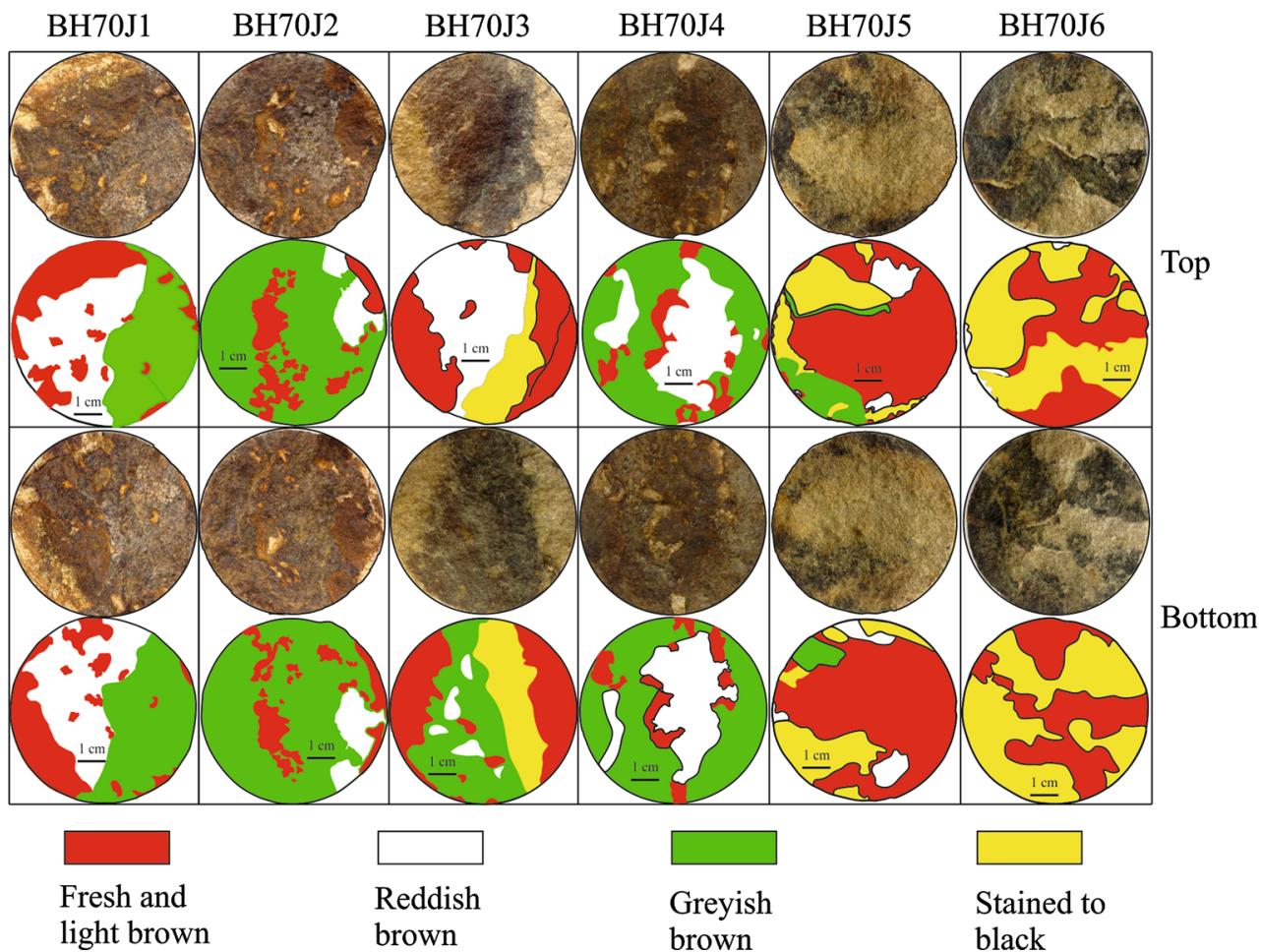

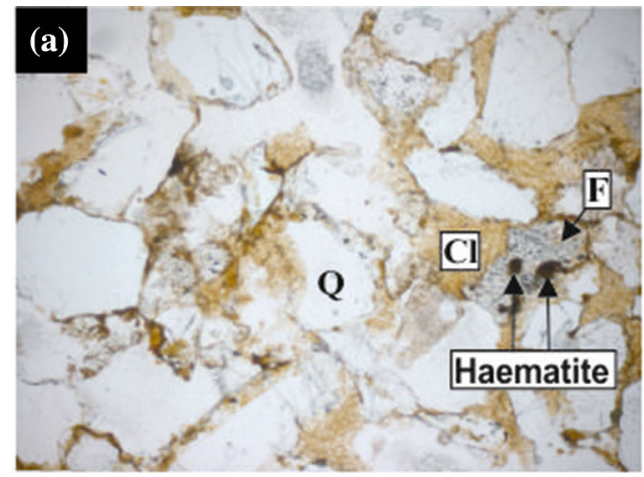
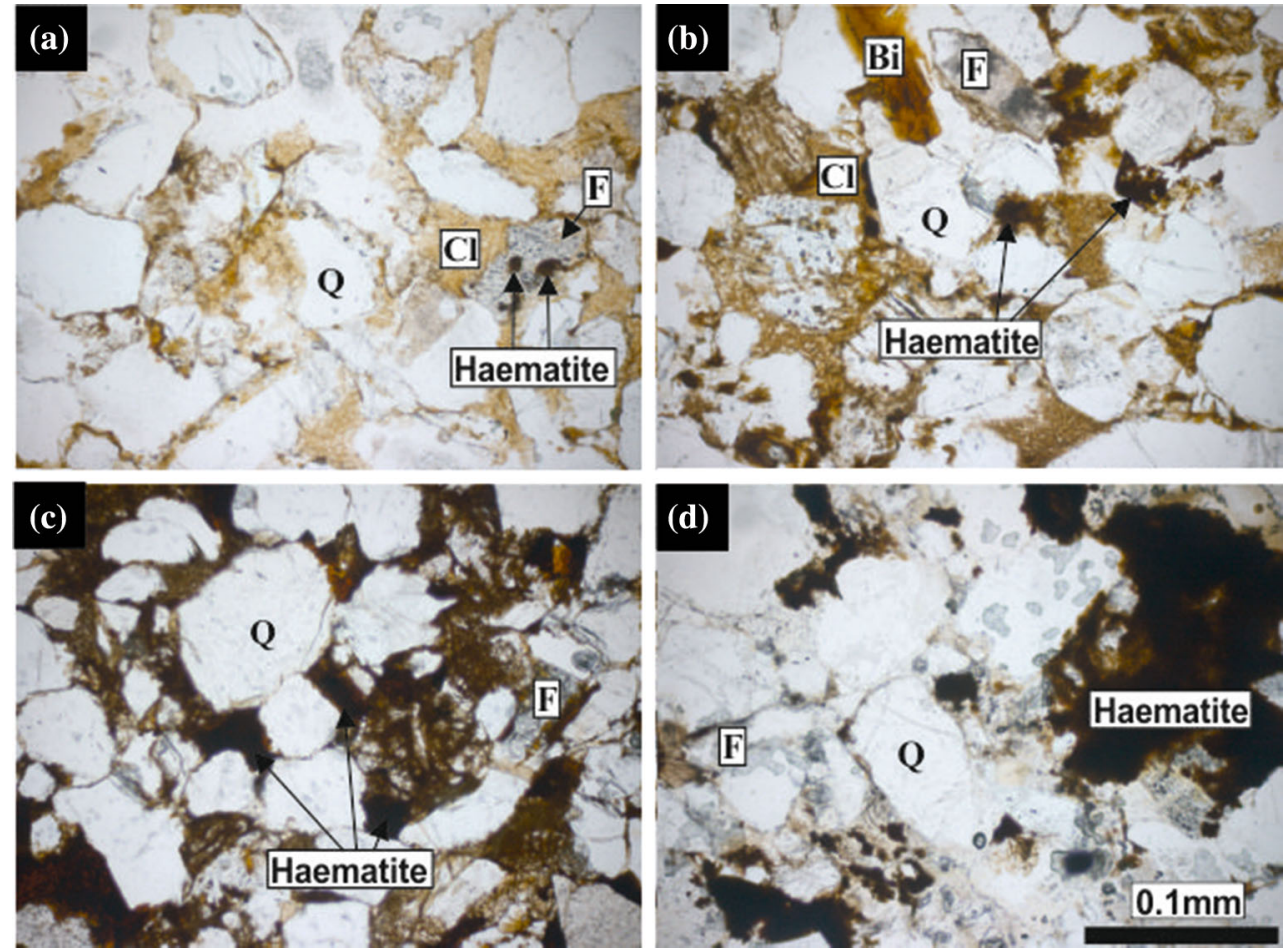

Fig. 12 Photomicrographs of thin sections from different coloured areas on incipient joint surfaces. Thin section samples were produced by cutting locally from each area (approximately parallel to joint surface), i.e., a light-brown area representing a rock bridge, i.e. essentially fresh rock; b reddish-brown area; $\mathbf{c}$ and $\mathbf{d}$ greyish-brown and black-mottled areas. Clear grains are quartz (Q); cloudy grains

are feldspar $\left(\mathrm{KAlSi}_{3} \mathrm{O}_{8}\right)(\mathrm{F})$. Mottled light-brown areas present in $\mathbf{a}$ and $\mathbf{b}$ are Clay $(\mathrm{Cl})$. A small amount of biotite (Bi) exhibiting pleochrosim is also present in b. Iron oxides (Haematite) is present in increasing quantities in $\mathbf{a}$ and $\mathbf{b}$, $\mathbf{c}$ and $\mathbf{d}$, respectively, perhaps indicating that this represents a wreathing product on the discontinuity surface (colour figure online) 
can sometimes lead to significantly increased tensile and shear strength (Tating et al. 2015).

Petrographic thin sections were taken from variously coloured areas on the joint surfaces to investigate mineralogy. Figure 12a shows an area interpreted as part of a rock bridge in relatively fresh rock. Figure $12 \mathrm{~b}, \mathrm{~d}$ is for progressively darker coloured areas of joint surface. The increase in quantity of iron oxide minerals from Fig. 12a-d is considered indicative of degree of weathering although it is acknowledged that such discoloration is currently difficult to quantify and link to rate of weathering as discussed by Turkington and Paradise (2005).

\subsection{Samples Containing Mineral Veins}

Mineral veins often have long and complex geological histories, and therefore their geometries, thicknesses,

Table 4 Tensile strength of incipient filled veins

\begin{tabular}{llll}
\hline Sample & $\begin{array}{l}\text { Diameter } \\
(\mathrm{mm})\end{array}$ & $\begin{array}{l}\text { Tensile } \\
\text { strength } \\
(\mathrm{MPa})\end{array}$ & $\begin{array}{l}\text { Average } \\
\text { strength } \\
(\mathrm{MPa})\end{array}$ \\
\hline DR50C1 & 50 & 0.49 & 0.84 \\
DR50C2 & 50 & 0.62 & \\
DR50C3 & 50 & 1.15 & \\
DR50C4 & 50 & 1.09 & \\
DR50C5 & 50 & 7.13 & \\
DR70C1 & 70 & 0.28 & \\
DR70C2 & 70 & 0.44 & \\
DR70C3 & 70 & 0.11 & \\
DR70C4 & 70 & 6.68 &
\end{tabular}

Samples DR50C5 and DR70C4 are not included in the process of average strength calculation

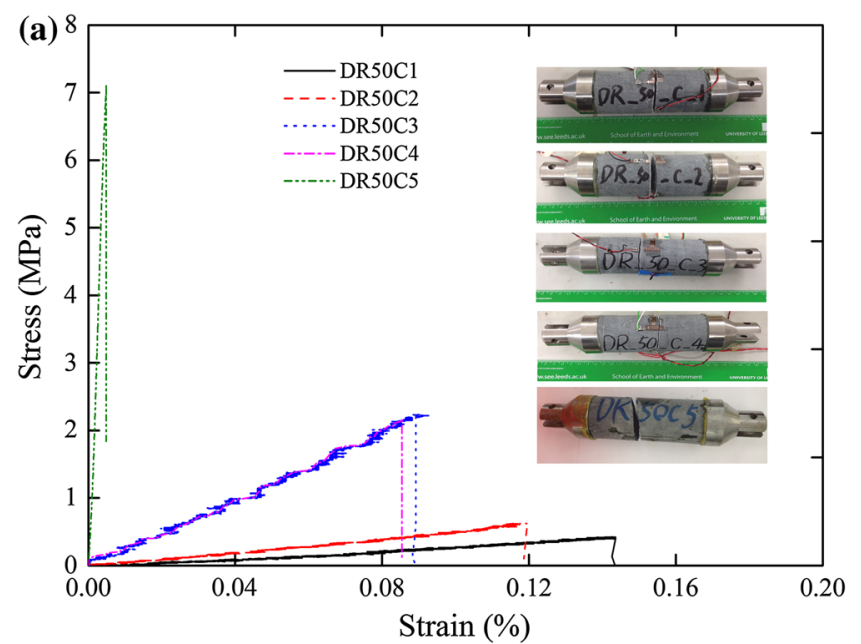

terminations and compositions are similarly complex, even at a small scale (Turichshev and Hadjigeorgiou 2014). For this set of tests, samples were cored with diameters of 50 and $70 \mathrm{~mm}$. The incipient predominantly calcite vein thicknesses typically ranged from 0.5 to $1.0 \mathrm{~mm}$. It was found that all samples failed at the vein walls and Table 4 provides a summary of test results, which varied between 0.11 and $7.13 \mathrm{MPa}$.

Figure 13a presents the stress versus strain curves for the 50-mm-diameter samples together with photographs of each test; Fig. 13b presents data from the $70-\mathrm{mm}$-diameter samples. As for the tests on incipient bedding planes presented in Fig. 9, stress-strain curves were essentially linear through to failure for all samples.

Figure 14 shows the surfaces of mineral veins exposed after failure. The data in Table 4 show that for two tests, much higher strengths were measured (6.68 and 7.13 MPa) than for all others, for which the measured UTS was typically less than $1 \mathrm{MPa}$. The feature that distinguishes these two samples is the presence of rock bridges of intact rock (with no mineral infill or coating). For sample DR50C5 the broken rock bridges are the discrete dark areas indicated by arrows in Fig. 14a. For sample DR70C4 there is one main rock bridge together with by many other discrete smaller rock bridges (Fig. 14b).

$\mathrm{X}$-ray diffraction analysis was used to identify the mineral composition of the veins. Three samples were prepared by scraping from pyritised and white vein segments, respectively, from sample DR50C1 (see Fig. 14a) and from the orange-tinted coating from sample DR70C1. Test results confirmed that calcite is the major mineral infill for all samples. The orange discolouration on the 70-mm-diameter samples is probably from iron oxide staining. The pyritised area from sample DR50C1 was

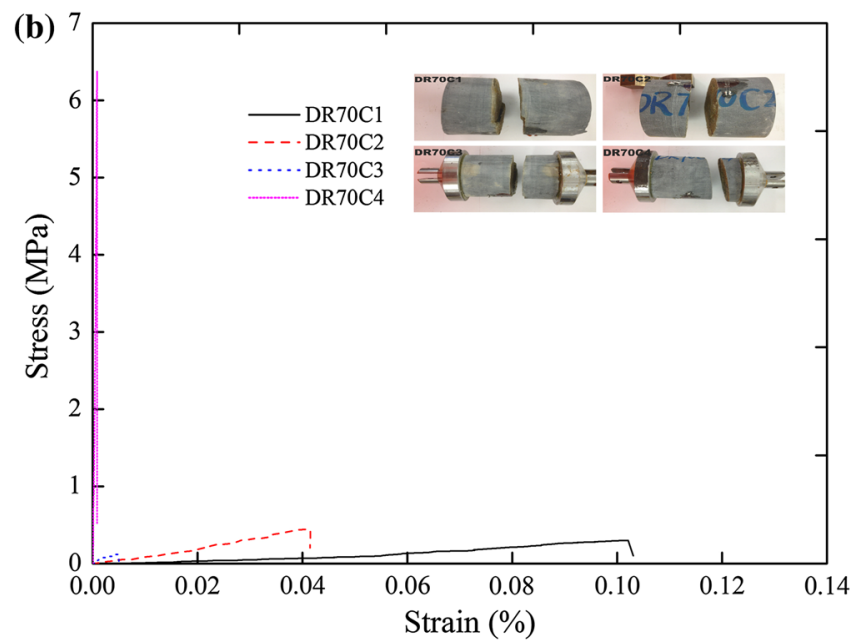

Fig. 13 Stress versus axial strain curves of samples with mineral veins under uniaxial tension. a Sample with a diameter of $50 \mathrm{~mm}$. b Sample with a diameter of $70 \mathrm{~mm}$. Each sample failed at the incipient mineral vein 


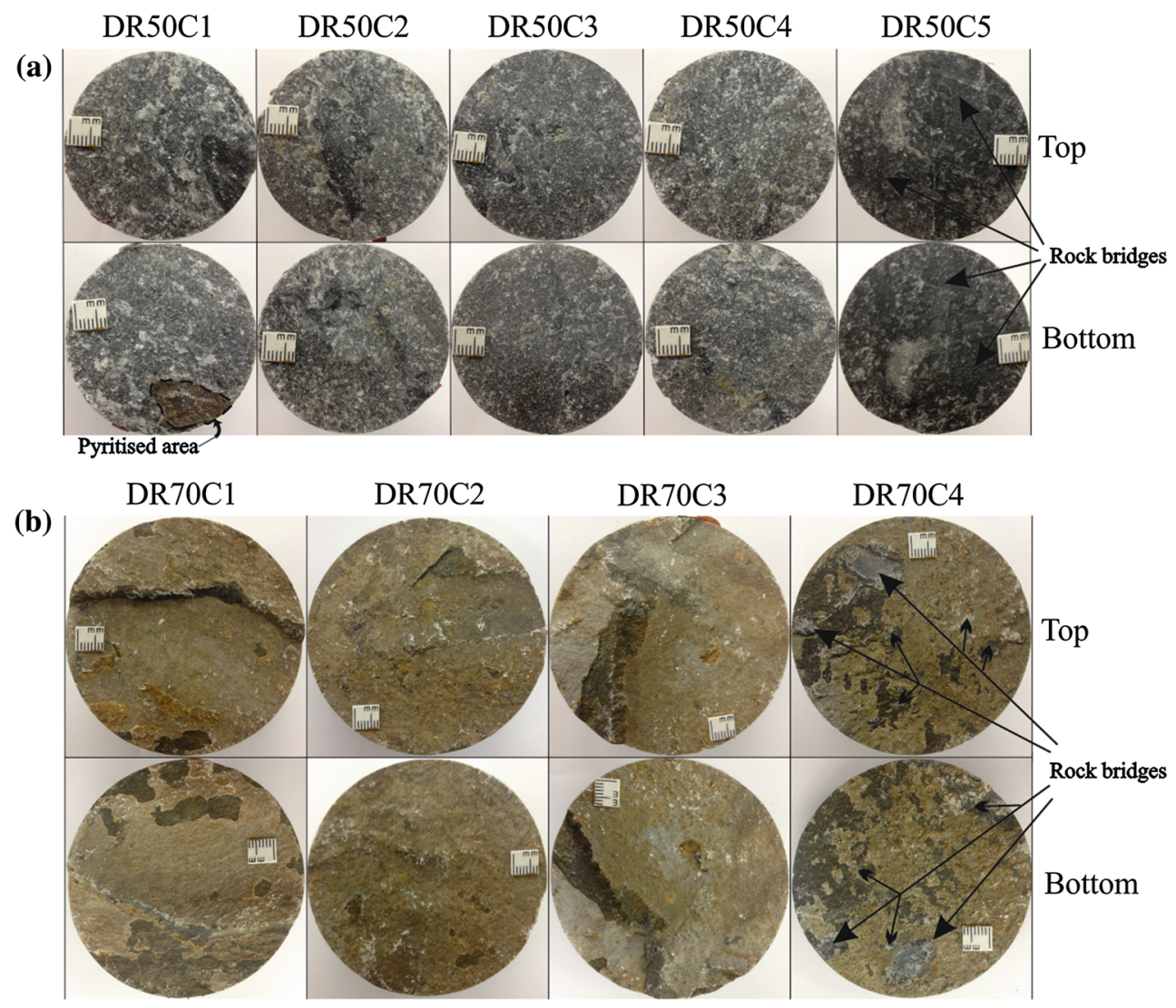

Fig. 14 Photographs of filled veins after uniaxial tension tests. a Vein profile with a diameter of $50 \mathrm{~mm}$. b Vein profile with a diameter of $70 \mathrm{~mm}$. Samples failed at one of the walls of the incipient

confirmed as pyrite but there is also calcite and a small amount of dolomite and quartz. For samples DR50C1, DR50C2, DR50C3 and DR50C4, failure surfaces were completely coated by calcite. As discussed above, samples DR50C5 and DR70C4 had rock bridges of intact siltstone with no mineral coating. Evidently these rock bridges have survived intact and unchanged from the original propagation of a fracture around them, long ago in geological time, leaving them as remnant intact rock surrounded by the mineral infilling what have been open fracture segments. The fracturing and mineralisation probably accompanied a mountain building episode in the late Silurian to early Devonian (Soper and Dunning 2005) as evident from the observed relationships between mineralisation, folding and faulting within the quarry.

\section{Discussion}

It has been found that all tested bedding planes have tensile strength less than the apparently homogeneous sections of the rock. It can be concluded that the incipiency of different bedding planes can be roughly characterised as a veins. Rock bridges along veins were revealed in samples DR50C5 and DR70C4. A small pyritised area was revealed on specimen DR50C1

percentage of UTS of the parent rock. For an individual bedding plane, UTS is likely to reduce with geological time from original stronger states eventually to fully persistent bedding-parallel discontinuities. As can be seen in Fig. 10, axial strain reduces markedly with measured UTS for equivalent stress levels; i.e. the tangent elastic modulus increases as weaker bedding planes (and adjacent relatively weak rock) are progressively removed (Fig. 15). It follows that the modulus must be extremely variable locally within a sample containing incipient discontinuities of differing strength.

The cohesion of an incipient joint can be caused by mineral bonding over areas of distinct rock bridge and by secondary cementation (Hoek 2007; Hencher 2012). For intermediate unfilled incipient joints (the type of incipient joints tested in the homogeneous sandstone samples reported in this paper), joint planes can be broadly divided into areas that comprise discrete rock bridge segments and persistent fracture segments (persistent areas). Hencher and Richards (2015) report shear test data from an intact rock bridge, revealed after shearing an incipient joint, with a cohesive strength of around $750 \mathrm{kPa}$ for the rock bridge area; persistent sections of joint contribute to shear strength but only in 


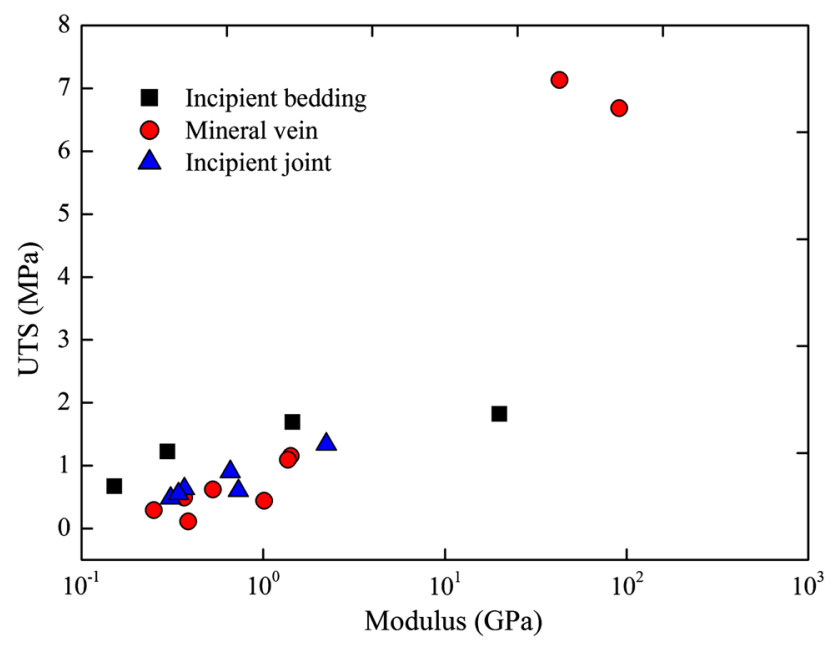

Fig. 15 Elastic modulus versus uniaxial tensile strength of geological discontinuities

terms of friction and roughness interactions. Regarding the relationship between UTS and modulus of incipient joints (Fig. 15), as for mineral veins, no clear relationship can be found between these two parameters. Modulus of tested samples of incipient joints ranged between 0.5 and $5 \mathrm{GPa}$, while UTS varied between 0.5 and $2 \mathrm{MPa}$.

Different sections of incipient discontinuity in the field may have different characteristics with some areas characterised by discrete rock bridges, others with mineral infill or precipitated weathering products and some sections open and with zero tensile strength. The rock bridge sections might be essentially large and discrete pillars or might comprise more diffuse areas with multitude small zones of intact contacts. A methodology is anticipated whereby strength contributions from the different segments of the discontinuity can be used to predict the overall shear or tensile strength and stiffness of the feature. This would be supported by geological analysis as to the origin and geological history that have resulted in the discontinuity characteristics in conjunction with strength tests. This subsequently might allow some predication of overall parameters for incipient joints with the same lithology and geological history based on visual inspection. That might be optimistic but must be better than current attempts at modelling rock masses that disregard such aspects completely leaving a situation that is best described as 'geological guesswork'.

In the tests reported here, colour variations of joint surfaces were associated with different degrees of weathering and/or mineral alteration products and hence potentially different tensile strengths. In this particular case (for the tests on joints), the strengths of rock bridges overshadowed contributions from coatings on persistent sections but there will be situations where contributions will come from various factors and sources. Procedures for back-analysing the contributions from each segment will be discussed in a separate paper.

Brzovic and Villaescusa (2007) produced a classification of mineral infill based on strength, and calcite (the major component of vein infill tested here) was graded as 'soft'. This is supported by the results of vein tests from this paper (Table 4), which show that the tensile strength is much lower for samples with calcite veins than for the intact rock. Where veins were combined with rock bridges of intact rock then the strength was much higher and in one case apparently much higher even than might be anticipated based on the rock bridge areas (DR70C4). For this case, the rock bridge areas are approximately $1555 \mathrm{~mm}^{2}$ (about $42 \%$ of the total cross section area). The tensile strength of these rock bridges of intact rock was calculated as $17.8 \mathrm{MPa}$ assuming zero strength elsewhere. This compares to the measured Brazilian tensile strength (12.5 MPa) for the intact rock. This might reflect some internal cementation and strengthening within the rock bridge area compared to the parent rock.

\section{Conclusions}

Tensile strength of geological discontinuities is usually neglected or underestimated by current standards (e.g. ISRM) and rock mechanics practitioners. Incipient rock discontinuities, however, may retain intermediate or high tensile strength-approaching and even exceeding that of the parent rock and will consequently strongly influence rock-engineering performance.

In this study, a series of uniaxial tension tests were carried on incipient geological discontinuities at laboratory scale including incipient bedding (bedding laminations), mineral veins and incipient rock joints. Tensile strength of these incipient features was identified.

Conclusions drawn from this study are as follows:

1. The direct tension test is useful to measure and research the UTS of visible and discrete incipient geological discontinuities. Incipient discontinuities can indeed have high tensile strength. In this series of experiments some discontinuities had tensile strength approaching that of the parent rock. Some are far weaker of course. The degree of development/incipiency of geological discontinuities can be expressed by their UTS relative to that of intact rock as suggested for broad characterisation by Hencher (2015).

2. Tests on weathered but incipient rock joints (with rock bridges) showed a clear relationship between UTS and area of rock bridges. The open, mineral coated sections of joint contributed little to the tensile strength. 
3. For tests on calcite veins the UTS was considerably lower than that of the intact rock. Where rock bridges were present as well as mineral infill, then the rock bridge strength dominated measured strength.

4. Sandstone samples containing incipient geological fractures always break through these weaker planes under direct tension. Geological discontinuities tested in this paper all exhibited brittle failure after direct tension at a low axial strain below $0.5 \%$.

5. The tangent elastic modulus increases as weaker bedding planes are progressively removed, i.e. the higher strength, the higher modulus. For mineral veins and incipient joints, however, no clear relations can be established between UTS and modulus.

Acknowledgments The China Scholarship Council and the University of Leeds provided financial support to this research. The support and practical assistance of the managers of Dry Rigg Quarry and Blackhill Quarry is gratefully acknowledged. Kirk Handley and John Martin are thanked for their support and constructive suggestions regarding the laboratory testing at the University of Leeds.

Open Access This article is distributed under the terms of the Creative Commons Attribution 4.0 International License (http://crea tivecommons.org/licenses/by/4.0/), which permits unrestricted use, distribution, and reproduction in any medium, provided you give appropriate credit to the original author(s) and the source, provide a link to the Creative Commons license, and indicate if changes were made.

\section{References}

Aitkenhead N, Barclay WJ, Brandon A, Chadwick RA, Chisholm JI, Cooper AH, Johnson EW (2002) The Pennines and adjacent areas, 4th edn. British Geological Survey, Nottingham, pp 8-14

Arthurton RS, Johnson EW, Mundy DJC (1988) Geology of the country around Settle. Memoir of the British Geological Survey, Sheet 60 (English and Wales)

Barla G, Innaurato N (1973) Indirect tensile testing of anisotropic rocks. Rock Mech Rock Eng 5:215-230

Brzovic A, Villaescusa E (2007) Rock mass characterization and assessment of block-forming geological discontinuities during caving of primary copper ore at the EI Teniente mine, Chile. Int J Rock Mech Min Sci 44:565-583

Cravero M, Iabichino G (2004) Analysis of the flexural failure of an overhanging rock slab. Int J Rock Mech Min Sci 41(3):605-610

Dan DQ, Konietzky H, Herbst M (2013) Brazilian tensile strength tests on some anisotropic rocks. Int J Rock Mech Min Sci 58:1-7

Deere DU (1968) Geological considerations. Chapter 1. In: Stagg KG, Zienkiewicz OC (eds) Rock mechanics in engineering practice. Wiley, New York, pp 1-20

Deere DU, Deere DW (1989) Rock quality designation (RQD) after twenty years. Contract Report GL-89-1, US Army Corps of Engineers, 67p plus Appendix

Erarslan N, Williams DJ (2012) Experimental, numerical and analytical studies on tensile strength of rocks. Int J Rock Mech Min Sci 49:21-30

Hashiba K, Fukui K (2014) Effect of water on the deformation and failure of rock in uniaxial tension. Rock Mech Rock Eng 47:1-11
Hawkes I, Mellor M, Gariepy S (1973) Deformation of rocks under uniaxial tension. Int J Rock Mech Min Sci Geomech Abstr 10:493-507

Hencher SR (2006) Weathering and erosion processes in rock implications for geotechnical engineering. In: Proceedings symposium on Hong Kong soils and rocks, March 2004. Institution of Mining, Metallurgy and Materials and Geological Society of London, pp 29-79

Hencher SR (2012) Practical engineering geology. Spon Press, Taylor \& Francis, Oxon

Hencher SR (2014) Characterizing discontinuities in naturally fractured outcrop analogues and rock core: the need to consider fracture development over geological time. Geol Soc Lond Spec Publ Adv Study Fract Reserv 374:113-123

Hencher SR (2015) Practical rock mechanics. Spon Press, Taylor and Francis, Oxon

Hencher SR, Knipe R (2007) Development of rock joints with time and consequences for engineering. In: Proceeding of the 11th congress of the international society of rock mechanics, Lisbon, Portugal

Hencher SR, Richards LR (2015) Assessing the shear strength of rock discontinuities at laboratory and field scales. Rock Mech Rock Eng 48:883-905

Hoek E (2007) Practical rock engineering. p 342. http://www. rocscience.com

ISRM (1978a) Suggested methods for the quantitative description of discontinuities in rock masses. Int $\mathrm{J}$ Rock Mech Min Sci Geomech Abstr 15:319-368

ISRM (1978b) Suggested methods for determining tensile strength of rock materials. Int J Rock Mech Min Sci Geomech Abstr 15:99-103

Khan AS, Irani FK (1987) An experimental study of stress wave transmission at a metallic-rock interface and dynamic tensile failure of sandstone, limestone and granite. Mech Mater 6:285-292

King WBR (1934) The lower palaeozoic rocks of Austwick and Horton-in-Ribblesdale, Yorkshire. Q J Geol Soc Lond 90:7-31

Kwansniewski M (2009) Testing and modelling of the anisotropy of tensile strength of rocks. Proceeding of the international conference on rock joints and jointed rock masses Arizona, United States

Li HB, Li JC, Bo L, Li JR, Li SQ, Xia X (2013) Direct tension test for rock material under different strain rates at quasi-static loads. Rock Mech Rock Eng 46:1247-1254

Liao JJ, Yang MT, Hsieh HY (1997) Direct tensile behaviour of a transversely isotropic rock. Int $\mathrm{J}$ Rock Mech Min Sci 34(5):837-849

Liu JF, Chen L, Wang C, Man K, Wang L, Wang J, Su R (2014) Characterizing the mechanical tensile behaviour of Beishan granite with different experimental methods. Int J Rock Mech Min Sci 69:50-58

Mier JGM, Shi C (2002) Stability issues in uniaxial tensile tests on brittle disordered materials. Int J Solids Struct 39:3359-3372

Okubo S, Fukui K (1996) Complete stress-strain curves for various rock types in uniaxial tension. Int $\mathrm{J}$ Rock Mech Min Sci 33(6):549-556

Paronuzzi P, Serafini W (2009) Stress state analysis of a collapsed overhanging rock slab: a case study. Eng Geol 108:65-75

Pells PJN (1993) Uniaxial strength testing. In: Hudson JA (ed) Comprehensive rock engineering, vol 3. Pergamon Press, Exeter, pp 67-85

Perras MA, Diederichs M (2014) A review of the tensile strength of rock: concepts and testing. Geotech Geol Eng 32:525-546

Saiang D, Malmgren L, Nodlund E (2005) Laboratory tests on shotcrete-rock joints in direct shear, tension and compression. Rock Mech Rock Eng 38(4):275-297 
Soper NJ, Dunning FW (2005) Structure and sequence of the Ingleton Group, basement to the central Pennines of northern England. Proc Yorks Geol Soc 55:241-261

Stevenson IP, Gaunt GD (1971) Geology of the country around Chapel-en-le-Frith. Memoir of the Geological Survey of Great Britain, Sheet 99 (English and Wales)

Tating F, Hack R, Jetten V (2015) Weathering effects on discontinuity properties in sandstone in a tropical environment: case study at Kota Kinabalu, Sabah Malaysia. Bull Eng Geol Environ 74:427-441

Turichshev A, Hadjigeorgiou J (2014) Experimental and numerical investigations into the strength of intact veined rock. Rock Mech Rock Eng 48:1897-1912
Turkington AV, Paradise TR (2005) Sandstone weathering: a century of research and innovation. Geomorphology 67:229-253

Wang W (2009) Rock mass mechanics (English edition). Central South University Press, Changsha

Waters CN, Aitkenhead N, Jones NS, Chisholm JI (1996) Late Carboniferous stratigraphy and sedimentology of the Bradford area, and its implications for the regional geology of northern England. Proceeding of the Yorkshire Geological Society 51(Part 2):87-101 